\title{
Ectrodactyly-ectodermal dysplasia-clefting (EEC) syndrome: dominant inheritance and variable expression
}

\author{
VICTOR B. PENCHASZADEH* and TERESA C. DE NEGROTTI
}

Sección de Genética Médica Policlinico de Niños, Buenos Aires, Argentina

\begin{abstract}
Summary. An infant is reported with a complete form of the ectrodactylyectodermal dysplasia clefting (EEC) syndrome, inherited from his mother, who has a partial expression of the condition, without clefting. This observation stresses the phenotypic variability of the EEC syndrome, which in most cases is inherited as an autosomal dominant with reduced penetrance.
\end{abstract}

The association of ectrodactyly, ectodermal dysplasia, and cleft lip and palate was recently stressed by Rüdiger, Haase, and Passarge (1970), though there are previous reports (see review by Bixler et al, 1971). Subsequent reports (Fried, 1972; Brill, Hsu, and Hirschhorn, 1972; Robinson, Wildervanck, and Chrong, 1973; Pries et al, 1974) have raised the question of possible genetic heterogeneity of this condition, based on phenotypic variability among different cases and on the existence of sporadic as well as familial cases. Most of the latter were incomplete forms of the syndrome inherited in dominant fashion, though Pries et al (1974) reported an instance of possible autosomal recessive inheritance. A greater insight into the confusing nosology of this disorder should be achieved by the study of intrafamilial variation in inherited cases.

The purpose of this communication is to report an infant with the complete triad of the EEC syndrome inherited from his mother: she is partially affected and lacks one major component of the condition.

\section{Case reports}

Case 1. The propositus is a 10-month-old boy, the only child of non-consanguineous parents. His head was normocephalic with sparse, dry, and hypopig-

Received 19 March 1975.

* Reprint requests to: Dr Victor B. Penchaszadeh, Sección de Genética Médica, Policlínico de Niños, Gallo 1330, Buenos Aires, Argentina. mented, greyish hair. The skin was fair, and sweating was normal; the nails were normal. He had cleft lip on the left side and complete cleft of the palate; there were 6 deciduous teeth of somewhat small size, peg-shaped and widely spaced (Fig. 1 and 2). Hands and feet had the lobster claw deformity, with bilateral absence of second and third fingers and of second, third, and fourth toes (Fig. 3). Pertinent radiographs showed absence of second and hypoplasia of third left metacarpals, and hypoplasia of right second and third metacarpals; both feet had complete absence of second, third, and fourth metatarsals and hypoplasia of middle and distal phalanges of fifth toes (Fig. 4).

An additional pertinent finding was abnormal accumulation of tears and dacryocystitis as a result of lacrimal puncta atresia. There was no obvious clinical evidence of hearing loss, and psychomotor development was normal.

Case 2. The mother of the propositus had sparse, dry, brittle, and hypopigmented scalp hair, scanty eyebrows, and fair skin; sweating was normal; nails were brittle and dystrophic. There was a history of abnormal accumulation of tears; deciduous and permanent dentition had been abnormal, with high level of caries and early dental decay; several teeth were lost and the remainder were small and peg-shaped. There was no evidence of hearing loss and mentality was normal.

She had bilateral absence of second and third fingers and camptodactyly of fourth and fifth fingers. The feet were asymmetrically affected: the right foot had an apparent duplication of the great toe with syndactyly, hypoplastic second toe with no nail, and complete syndactyly between third and fourth toes; the left foot had absence of second and third toes and syndactyly between the fourth and fifth toes (Fig. 5).

Radiographs revealed absence of second metacarpal, 
Fig. 1 and 2. Case 1. Note cleft lip and palate, scanty and hypopigmented hair, and peg-shaped teeth.
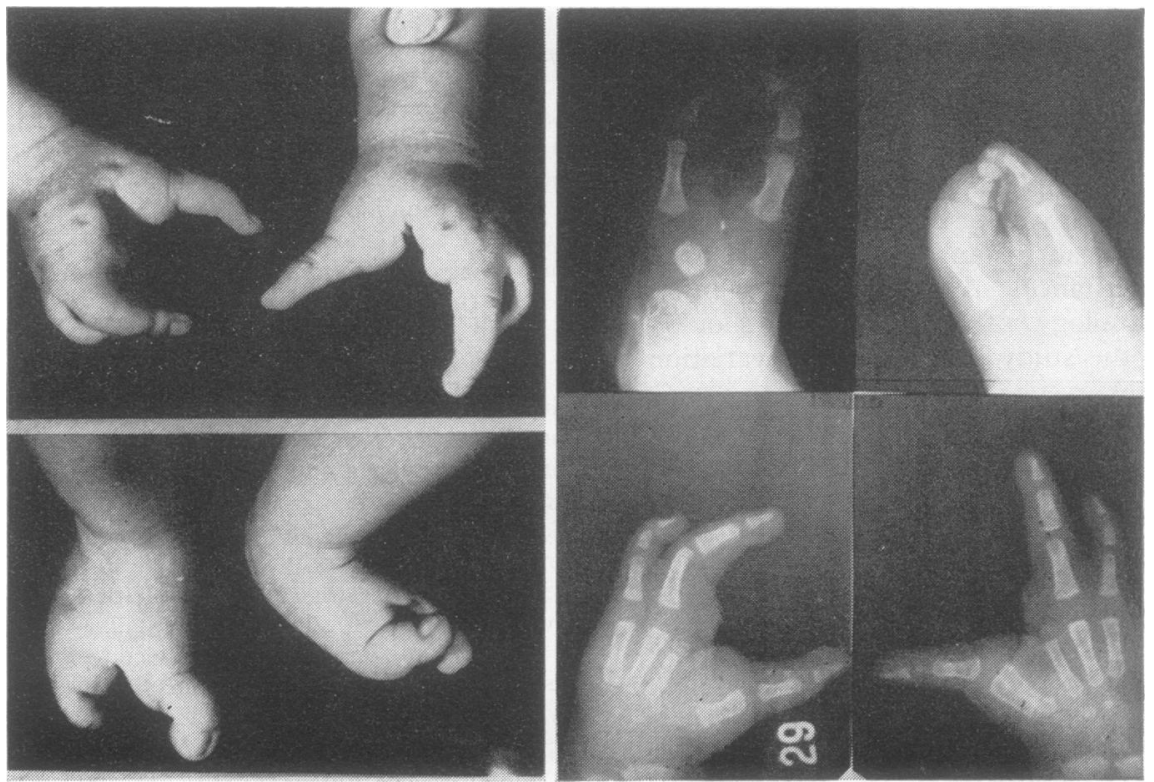

Fig. 3. Case 1. Symmetrical lobster claw deformities of hands and feet.

FIG. 4. Case 1. Radiographs of hands and feet. 

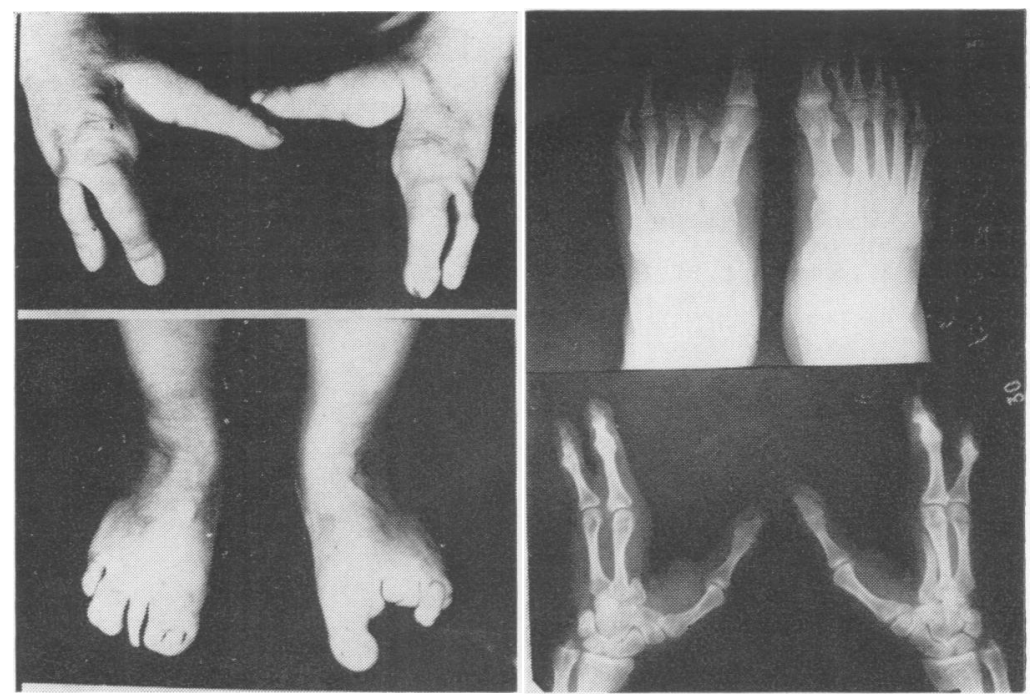

FIG. 5. Case 2. Deformities of hands and feet. FIG. 6. Case 2. Radiographs of hands and feet.

hypoplasia of third metacarpal, and hypoplasia of distal phalanges of both hands. The apparent duplication of the right great toe turned out to be a syndactyly between a duplicated second toe and the great toe; the left second and third metatarsals and the middle and distal phalanges on both feet were hypoplastic (Fig. 6).

There was no further history of ectrodactyly, cleft lip, or palate nor ectodermal dysplasia in the rest of the family.

\section{Discussion}

The phenotypic variability of the EEC syndrome and the existence of sporadic as well as familial cases have raised the question of genetic heterogeneity in this condition. Pries et al (1974) suggested a differentiation between 'complete' and 'incomplete' forms of the syndrome, the former tending to be sporadic and the latter familial. The present report, however, demonstrates the existence of both forms in the same family: the propositus had the complete triad of the condition while his mother was affected with ectrodactyly of hands and feet plus several signs of ectodermal dysplasia (dental decay, small peg-shaped teeth, scanty hair and eyebrows, nail dystrophy), but no clefting of lip or palate.

In the family reported by Brill et al (1972), none of the four affected members had the complete triad of the syndrome: ectrodactyly was present in all, but cleft lip or palate was present in only two, one of whom apparently lacked any signs of ectodermal dysplasia; ectodermal abnormalities, on the other hand, were present in two members with no clefting. In another family (Robinson et al, 1973) a mother with cleft lip and palate, syndactyly of hands and feet, hypodontia and conductive hearing loss had a son with syndactyly of fingers, claw feet, and hypodontia.

These previous instances of intrafamilial variation and the evidence presented in this report indicate the wide phenotypic spectrum of the syndrome, in which each of the major components may be variable in its expression, even to the point of complete lack, as was so in Case 2 of this report. It seems, therefore, that the lack of one of the major components of the triad should not, per se, exclude the diagnosis of the EEC syndrome. The simplest explanation of these findings is that the condition is the result of a single gene dominantly inherited with reduced penetrance, that could account for the incomplete forms; sporadic cases would represent new mutations.

The two reports of familial cases with normal parents (Walker and Clodius, 1963; Pries et al, 1974) have raised the possibility of autosomal recessive inheritance of the EEC syndrome; incomplete penetrance of a dominant gene, however, could account for these findings as well. It will, therefore, be necessary to search and document rigorously the mildest manifestations of this condition in first degree relatives of affected individuals before a better delineation of the EEC syndrome is achieved and its possible genetic heterogeneity elucidated. 


\section{REFERENCES}

Bixler, D., Spivack, J., Bennett, J., and Christian, J. C. (1971). The ectrodactyly-ectodermal dysplasia-clefting (EEC) syndrome. Clinical Genetics, 3, 43-51.

Brill, C. B., Hsu, L. Y., and Hirschhorn, K. (1972). The syndrome of ectrodactyly, ectodermal dysplasia and cleft lip and palate: report of a family demonstrating a dominant inheritance pattern. Clinical Genetics, 3, 295-302.

Fried, K. (1972). Ectrodactyly-ectodermal dysplasia-clefting (EEC) syndrome. Clinical Genetics, 3, 396-400.

Pries, C., Mittelman, D., Miller, M., Solomon, L. M., Pashayan,
H. M., and Pruzansky, S. (1974). The EEC syndrome. American Fournal of Diseases of Children, 127, 840-844.

Robinson, G. C., Wildervanck, L. S., and Chrong, T. P. (1973). Ectrodactyly, ectodermal dysplasia and cleft lip-palate syndrome: its association with conductive hearing loss. Fournal of Pediatrics, 82, 107-109.

Rüdiger, R. A., Haase, W., and Passarge, E. (1970). Association of ectrodactyly, ectodermal dysplasia and cleft lip-palate. American Fournal of Diseases of Children, 120, 160-163.

Walker, J. C. and Clodius, L. (1963). The syndrome of cleft lip, cleft palate and lobster claw deformities of hands and feet. Plastic and Reconstructive Surgery, 32, 627-636. 